\title{
Hastaların Periyodik Sağlık Muayenesi Hakkındaki Farkındalıkları ve Kullanım Durumları-Düzce îli Örneği
}

\author{
Awareness of Patients About Periodic Health Examination and Usage \\ Situations-Düzce Province Example
}

Zerrin GAMSIZKAN $\mathbb{D}$, Abdulkadir KAYA

Düzce Üniversitesi Tıp Fakültesi, Aile Hekimliği Anabilim Dalı, Düzce, Türkiye

ORCID ID: Zerrin Gamsızkan 0000-0001-8677-4004, Abdulkadir Kaya 0000-0003-1725-1220

Bu makaleye yapılacak atıf: Gamsızkan Z ve Kaya A. Hastaların Periyodik Sağıı Muayenesi Hakkındaki Farkındalıkları ve Kullanım DurumlarıDüzce İli Örneği. Med J West Black Sea. 2021;5(2):281-286.

Sorumlu Yazar

Zerrin Gamsızkan

E-posta

zgamsizkan@yahoo.com
Geliș Tarihi

15.04.2021

Revizyon Tarihi

18.05.2021

Kabul Tarihi

21.05.2021
Öz

Amaç: Periyodik sağlık muayenesi; bir hastalık belirtisi göstermeyen sağlıklı kişilerin, tarama muayene ve testleri ile, danışmanlık ile sağlıklarının korunmasına katkıda bulunmak amacıyla yapılan düzenli sağlık kontrolüdür. Bu çalışmanın amacı, toplumun periyodik sağlık muayeneleri (PSM) hakkındaki bilgi ve tutumunu belirlemek ve hastaların PSM yaptırma durumunu etkileyen faktörleri tartışmaktır.

Gereç ve Yöntemler: Çalışma tanımlayıcı kesitsel olarak tasarlanmıştır. Çalışmada Düzce Tıp Fakültesi polikliniklerine Mayıs 2021 tarihleri arasında başvuran hastalara araştırmacılar hazırlanan PSM hakkında 22 soruluk bir anket uygulanmıştır.

Bulgular: Çalışmaya 728 kişi dahil edildi. Katıımcıların \%46,6'sı ( $n=339)$ kadın, \%53,4'ü ( $n=389)$ ise erkekti. Katıımcıların yaş ortalaması 38,91 $\pm 13,8$ yıldı. Katılımcıların $\% 16,22$ 'si $(n=118)$ düzenli tetkik yaptırdığını, \%83,8'i $(n=610)$ ise düzenli tetkik yaptırmadığını ifade etti. Gaytada gizli kan tahlili yaptırma durumunun yaş ile ilişkisi bulunmazken; daha önce rahim ağzı kanseri için muayene olanlar $(p=0,007)$ ve aile hekimine meme muayenesi yaptıranların $(p=0,039)$ anlamlı derecede daha ileri yaşta oldukları görüldü. Ailesinde kardiyovasküler hastalığı olanların daha fazla oranda düzenli tetkik yaptırdığı görüldü $(p<0,001)$.

Sonuç: Çalışmamızda ortaya çıkan en önemli sonuç, katılımcıların büyük bir çoğunluğunun düzenli PSM ve tarama tetkiklerini yaptırmıyor olmasıdır. Birinci basamak hekimlerinin bireyleri PSM konusunda bilgilendirmesi gerekmektedir.

Anahtar Sözcükler: Periyodik sağlık muayenesi, Kanser tarama, Birinci basamak sağlık hizmetleri

\section{ABSTRACT}

Aim: Periodic health examination; It is a regular health check performed to contribute to the protection of the health of healthy people who do not show any signs of illness with screening, examination and tests, counseling. The aim of this study is to determine the knowledge and attitude of the society about Periodic Health Examinations and to discuss the factors that affect the status of patients to have regular periodic health check-ups.

Material and Methods: The study is designed as a descriptive cross-section. For the study, a questionnaire consisting of 22 questions prepared by researchers was filled out to patients who applied Düzce Medical Faculty polyclinics between 15. 03. 2021- 25.03.2021.

Results: 728 people were included in the study. $46.6 \%(n=339)$ of the participants were female and $53.4 \%(n=389)$ were male. The average age of the participants was calculated as $38.91 \pm 13.8 .16 .22 \%$ $(n=118)$ of the participants stated that they had regular examinations, and $83.8 \%(n=610)$ did not have regular examinations. While there was no relationship between the condition of having a DDH 
analysis before, with age; those who had a previous examination for cervical cancer $(p=0.007)$ and those who had a breast examination by their family doctor $(p=0.039)$ were significantly older. It was observed that those with a family history of cardiovascular disease had regular examinations at a higher rate $(p<0.001)$.

Conclusion: The most important result of our study is that the majority of the participants did not have regular PSM and screening tests. Both primary care physicians and community health healthcare professionals are required to inform the public about periodic health examinations.

Keywords: Periodic health examination, Cancer screening, Primary care

\section{GiRiş}

Periyodik sağlık muayenesi kavramı, hastalıkların erken tespiti ve bu şekilde sağlığı geliştirme amacıyla çok eski zamanlarda ortaya çıkmıştır (1). Tanım olarak periyodik sağlık muayenesi (PSM) sağlıklı bireylerin danışmanlık, fizik muayene, bağışıklama, laboratuvar incelemeleri gibi işlemler kullanılarak belirli aralıklarla değerlendirilmesidir (2). PSM'nde temelde amaçlanan hastalıkları oluşmadan önlemektir. Önleme, tedavinin aksine hastalığı önlemek için alınan önlemler, tarama ve periyodik tıbbi muayenelerden oluşmaktadır. Tarama ve periyodik tıbbi muayeneler, hastalıkların erken aşamada, herhangi bir belirti göstermeden teşhis edilmesine yardımcı oldukları için koruyucu sağlık hizmetlerinin en önemli bileşenleridir (3). PSM sadece bireyi korumaz, toplumun da bütünsel olarak sağlığını geliştirir. Ülkemizde de birinci basamak hekimleri tarafından aile hekimliği yönetmeliğinde çerçevesi çizilmiş kanıta dayalı, yapılandırılmış PSM yapılmakta ve bireyler düzenli sağlık taramalarına özendirilmektedir (4). PSM, aile hekimliği yönetmeliğinde önerilen periyodik muayene ve tarama testleri konusunda kişinin rızası da olması gerekmektedir. Bu bağlamda tarama yaptırma isteği olmayan ya da periyodik sağlık muayenesi konusunda farkındalığı olmayan bir hastanın ideal düzeyde sağlığı geliştirilemeyecektir.

PSM ile gerçekleştiren düzenli sağlık takiplerinin kazanımları toplumun ve bireyin sağlığını geliştirdiği açıkça gösterilmiş olmasına rağmen, hâlen istenilen düzeyde değildir. Bunun bir nedeni olarak hastaların PSM hakkındaki inanç ve tercihlerinin önemli olabileceği düşünülmektedir. Araştırmacılar ayrıca, her toplumun kendine özgü dinamikleri olduğu için bölgesel olarak o toplumun düzenli sağlık muayenelerini takip etme eğilimini okumak gerektiğini de eklemektedirler (5). Hastaların PSM yaptırma konusundaki inançlarını ve yaklaşımlarını anlamak hastalıkları oluşmadan önleyebilme stratejilerine yol gösterebilir. Bu çalışmanın amacı bireylerin PSM hakkındaki bilgi ve tutumlarını belirlemek ve hastaların PSM yaptırma durumunu etkileyen faktörleri araştırmaktır. Çalışma sonuçlarının tartışılması, PSM konusunda hekimlerin farkındalığını artıracak ve literatüre katkı sağlayacaktır.

\section{GEREÇ ve YÖNTEMLER}

Çalışma tanımlayıcı kesitsel olarak tasarlanmıştır. Çalışma için Düzce Üniversitesi Tıp Fakültesi Etik Kurul'undan onay alınmıştır (Protokol No:2021/73). Düzce Tıp Fakültesi ayaktan hasta polikliniğine 15.03.2021- 25.03.2021 tarihleri arasında başvuran hastaların sağlıklı oldukları dönemde PSM hakkındaki düşünceleri sorgulanmıştır. Araştırmacılar tarafından 22 soruluk bir anket hazırlanmıştır. Ankette; yaş, cinsiyet, öğrenim durumu, meslek gibi sosyodemografik verilerin yanı sıra, kronik hastalık varlığı, ailede kronik hasta veya kanser varlığı ve periyodik sağlık taramaları yaptırma durumunu sorgulayan sorular mevcuttu. Hazırlanan anket öncelikle 30 kişiye uygulanmış, anlaşılmayan sorular revize edilmiştir. Son düzenlemelerle nihai hâlini alan anket hazır hâle getirilmiştir. Çalışma için dahil olma kriterleri 18 yaş üstü olmak, okuma yazma biliyor olmak olarak belirlenmiştir. Çalışmanın hariç tutma kriteri ise; anket sorularını anlayamayacak düzeyde akıl hastalığı olmak olarak belirlenmiştir. Çalışma örneklemi için güç analizi yapılmıştır. Literatürde yapılan çalışmalar incelendiğinde çalışmanın temel sonuçlarından biri olan düzenli tetkik yaptırma durumu dikkate alınarak bir güç analizi yapılmıştır. Benzer çalışmalar dikkate alınarak örneklem büyüklüğü Tip I hata $(0,05)$, ile çalışmaya dahil edilen 728 kişi dikkate alındığında çalışmanın gücü \%84 olarak hesaplanmıştır.

\section{İstatistiksel Analiz}

Analizlerde SPSS 23.0 paket programı kullanıldı. Çalışmanın istatistiği yapılırken tanımlayıcı istatistiklerde numerik veriler ortalama ve standart sapma, kategorik veriler ise sayı ve yüzde olarak verildi. Numerik verilerin dağılımına histogram grafikleri ile bakıldı. İki ayrı grupta numerik veriler Student t testi, ikiden fazla grupta numerik veriler Oneway ANOVA ile analiz edildi. Çoklu analizlerde gruplar arası ilişkiye Tukey tetsi ile bakıldı. Ayrıca bağımsız iki kategorik verinin karşılaştırılması için ki-kare testi kullanıldı. P anlamlılık değeri $<0,05$ olarak kabul edildi.

\section{BULGULAR}

Çalışmaya 728 kişi dahil edildi. Katılımcıların \%46,6'sı ( $n=339)$ kadın, \%53,4'ü $(n=389)$ ise erkekti. Katılımcıların

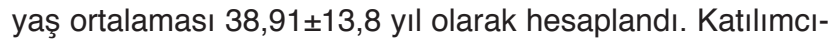
ların \%57,3'ü ( $n=417)$ evli, \%35,7'si $(n=260)$ bekâr, \% 51'i $(n=7)$ ise dul olduğunu ifade etti. Diğer tüm sosyodemografik veriler Tablo 1'de verilmiştir.

Katılımcılara genel sağlık durumlarının nasıl olduğu soruldu ve katılımcıların \%53,8(n=392)'i genel sağlık durumunu orta 
Tablo 1: Sosyodemografik veriler

\begin{tabular}{lcc}
\hline \multicolumn{1}{l}{ Sosyodemografik özellikler } & $\mathbf{n}(\%)$ \\
\hline Cinsiyet & Kadın & $339(46,6)$ \\
& Erkek & $389(53,4)$ \\
\hline Medeni durum & Evli & $417(57,3)$ \\
& Bekar & $260(35,7)$ \\
\hline Meslek & Dul & $51(7,0)$ \\
& Ev hanımı & $139(19,1)$ \\
& İşçi & $126(17,3)$ \\
& Memur & $186(25,5)$ \\
& Serbest & $118(16,2)$ \\
& Öğrenci & $80(11,0)$ \\
Eğitim durumu & Emekli & $79(10,9)$ \\
& İlkokul & $145(19,9)$ \\
& Lise & $303(41,6)$ \\
& Üniversite & $280(38,5)$ \\
\hline Gelir durumu & Yeterli & $154(21,2)$ \\
& Orta & $479(65,8)$ \\
& Yetersiz & $95(13,0)$ \\
\hline
\end{tabular}

olarak belirtti. Çalışmaya katılan bireyler çoğunlukla aile hekimlerinden memnun olduğunu söyledi (\%64,3). Katılımcıların \%16,22'si ( $n=118$ ) düzenli PSM yaptırdığını, \%83,8'i $(n=610)$ ise PSM yaptırmadığını ifade etti. Katılımcıların PSM yaptırmama sebepleri sorulduğunda; \%42'si (n=306) “Gerek olmadığını düşünüyorum”, \%22,7'si (n=165) "Vaktim yok", \% 19'u (n=138) ise "Kötü bir sonuç çıkmasından korkuyorum" şeklinde cevaplar verdiği görüldü. Katılımcıların PSM ve bazı diğer sağlıkla ilgili özellik ve davranışlarına ait veriler Tablo 2'de verilmiştir.

Katılımcıların yaşlarına göre bazı sorulara verdiği cevaplar değerlendirildi. Yaş ile aile hekimine başvuru arasında anlamlı farklılık olduğu görüldü $(p<0,001)$. Aile hekiminden memnuniyetin yaş ile ilişkisi bulunmadı $(p=0,435)$. Aile hekimlerinden PSM için danışmanlık alanların anlamlı genç yaşta oldukları görüldü $(p<0,001)$. Katılımcılardan PSM yaptıranların anlamlı olarak daha ileri yaşta oldukları görüldü ( $p<0,001)$. Daha önce GGK tahlili yaptırma durumunun yaş ile ilişkisi bulunmazken; daha önce rahim ağzı kanseri için muayene olanlar $(p=0,007)$ ve aile hekimine meme muayenesi yaptıranların $(p=0,039)$ anlamlı derecede daha ileri yaşta oldukları görüldü.

Katılımcıların PSM yaptırma durumu dul ve evli olanlarda bekârlara göre anlamlı fazlaydı $(p<0,001)$. PSM yaptırmama oranları ilkokul düzeyi eğitim seviyesi olanlarda diğer eğitim seviyesi olanlara göre anlamlı fazlaydı $(p<0,001)$. Meslek ile PSM yaptırma durumu arasında anlamlı farklııklar izlendi $(p<0,001)$. Yine ailede $\mathrm{KVH}$ olanların daha fazla
Tablo 2: PSM ve bazı diğer sağlıkla ilgili özellik ve davranışlarına ait veriler

\begin{tabular}{|c|c|c|}
\hline & & n (\%) \\
\hline \multirow{3}{*}{$\begin{array}{l}\text { Genel sağlık } \\
\text { durumunuz nasıl? }\end{array}$} & İyi & $123(16,9)$ \\
\hline & Orta & $392(53,8)$ \\
\hline & Kötü & $213(29,3)$ \\
\hline \multirow[t]{3}{*}{$\begin{array}{l}\text { Sigara içme } \\
\text { durumu }\end{array}$} & Evet & $141(19,4)$ \\
\hline & Hayır & $572(78,6)$ \\
\hline & Bırakmış & $15(2,1)$ \\
\hline \multirow[t]{4}{*}{ PSM nedir? } & Bir fikrim yok & $116(15,9)$ \\
\hline & Düzenli tetkik yaptırmak & $359(49,3)$ \\
\hline & $\begin{array}{l}\text { Zaman zaman } \\
\text { muayene olmak }\end{array}$ & $143(19,6)$ \\
\hline & $\begin{array}{l}\text { Hastalıklara } \\
\text { yakalanmadan önce } \\
\text { tespit etmek amaçlı } \\
\text { muayene olmak }\end{array}$ & $110(15,1)$ \\
\hline \multirow[t]{2}{*}{$\begin{array}{l}\text { Aile hekiminden } \\
\text { memnuniyet }\end{array}$} & Memnunum & $468(64,3)$ \\
\hline & Memnun değilim & $66(9,1)$ \\
\hline \multirow[t]{3}{*}{$\begin{array}{l}\text { Aile hekimine } \\
\text { başvuru }\end{array}$} & Hiç gitmedim & $194(26,6)$ \\
\hline & $\begin{array}{l}\text { Her hastalığımda önce } \\
\text { aile hekimine giderim }\end{array}$ & $463(63,6)$ \\
\hline & Seyrek giderim & $71(9,8)$ \\
\hline \multirow{2}{*}{$\begin{array}{l}\text { PSM ile ilgili } \\
\text { aile hekiminden } \\
\text { danışmanlık }\end{array}$} & Evet & $305(41,9)$ \\
\hline & Hayır & $423(58,1)$ \\
\hline \multirow[t]{2}{*}{ Ailede KVS } & Evet & $211(29,0)$ \\
\hline & Hayır & $517(71,0)$ \\
\hline \multirow{2}{*}{$\begin{array}{l}\text { Daha önce GGK } \\
\text { tahlili (50-70 yaş } \\
\text { arası) }\end{array}$} & Evet & $62(8,5)$ \\
\hline & Hayır & $115(15,8)$ \\
\hline \multirow{2}{*}{$\begin{array}{l}\text { Daha önce rahim } \\
\text { ağzı kanseri için } \\
\text { muayene (30-65 } \\
\text { yaş arası kadınlar) }\end{array}$} & Evet & $25(3,4)$ \\
\hline & Hayır & $211(29,0)$ \\
\hline \multirow{2}{*}{$\begin{array}{l}\text { Aile hekimi meme } \\
\text { muayenesi ( } 40 \text { yaş } \\
\text { üstü kadınlar) }\end{array}$} & Evet & $8(1,1)$ \\
\hline & Hayır & $122(16,8)$ \\
\hline \multirow{2}{*}{$\begin{array}{l}\text { Mamografi çekilme } \\
\text { (40 yaş üstü } \\
\text { kadınlar) }\end{array}$} & Evet & $50(6,9)$ \\
\hline & Hayır & $80(11,0)$ \\
\hline \multirow[t]{2}{*}{$\begin{array}{l}\text { Ailede kanser } \\
\text { hastası }\end{array}$} & Evet & $211(29,0)$ \\
\hline & Hayır & $517(71,0)$ \\
\hline
\end{tabular}

*PSM: Periyodik Sağlık Muayenesi, ${ }^{* * K V H: ~ K a r d i y o v a s k u ̈ l e r ~}$ hastalık, GGK 
oranda PSM yaptırdığı görüldü $(p<0,001)$. Diğer demografik veriler ile PSM yaptırma oranları arasında anlamlı farklılık izlenmedi ( $p>0,05)$ (Tablo 3).

Tablo 3: Düzenli PSM yaptırma durumu ile sosyo-demografik özelliklerin ilişkisi

\begin{tabular}{|c|c|c|c|c|}
\hline & & \multicolumn{2}{|c|}{ PSM yaptırma } & \multirow[b]{2}{*}{$\mathbf{P}$} \\
\hline & & $\begin{array}{c}\text { Evet } \\
(n=118)\end{array}$ & $\begin{array}{c}\text { Hayır } \\
(n=610)\end{array}$ & \\
\hline \multirow[t]{3}{*}{ Cinsiyet } & Erkek & 73 & 316 & 0,045 \\
\hline & Kadın & 45 & 294 & \\
\hline & Erkek & 73 & 316 & \\
\hline \multirow{3}{*}{$\begin{array}{l}\text { Medeni } \\
\text { durum }\end{array}$} & Evli & 96 & 321 & $<0,001$ \\
\hline & Bekâr & 6 & 254 & \\
\hline & Dul & 16 & 35 & \\
\hline \multirow{3}{*}{$\begin{array}{l}\text { Eğitim } \\
\text { durumu }\end{array}$} & İlkokul & 42 & 103 & $<0,001$ \\
\hline & Lise & 39 & 264 & \\
\hline & Üniversite & 37 & 243 & \\
\hline \multirow[t]{3}{*}{ Gelir } & Yeterli & 32 & 122 & 0,062 \\
\hline & Orta & 77 & 402 & \\
\hline & Yetersiz & 9 & 86 & \\
\hline \multirow[t]{3}{*}{ Sigara } & Evet & 22 & 119 & 0,906 \\
\hline & Hayır & 93 & 479 & \\
\hline & Bırakmış & 3 & 12 & \\
\hline \multirow[t]{6}{*}{ Meslek } & Ev hanımı & 28 & 111 & $<0,001$ \\
\hline & İşçi & 12 & 114 & \\
\hline & Memur & 29 & 157 & \\
\hline & Serbest meslek & 8 & 110 & \\
\hline & Öğrenci & 4 & 76 & \\
\hline & Emekli & 37 & 42 & \\
\hline \multirow{2}{*}{$\begin{array}{l}\text { Ailede } \\
\text { KVH varlığı }\end{array}$} & Evet & 86 & 125 & $<0,001$ \\
\hline & Hayır & 32 & 485 & \\
\hline
\end{tabular}

Ailesinde kanser hastası olan bireylerin anlamlı derece daha çok GGK tahlili yaptırdığı görüldü $(p=0,007)$. Yine ailesinde kanser hastası olanların anlamlı derecede daha çok mamografi yaptırdığı görüldü ( $p<0,001)$ (Tablo 4).

\section{TARTIŞMA}

$\mathrm{Bu}$ çalışmada üçüncü basamak bir üniversite hastanesine başvuran hastaların düzenli PSM ve tarama tetkiklerini yaptırma durumu ve konu hakkındaki bilgi ve bakış açısı inceIenmiştir. Çalışma sonuçlarında, katılımcıların büyük bir çoğunluğunun düzenli periyodik sağlık muayenesi ve tarama tetkiklerini yaptırmadığı tespit edilmiştir. Katılımcıların yaklaşık üçte biri PSM yaptırmama nedenini" Düzenli tetkikin gereksiz" olduğu şeklinde ifade etmiştir. PSM yaptırmayan katılımcıların yaklaşık yarısı, kötü bir sonuçla karşılaşmak istemediği için yaptırmadığını söylemiştir. Olumsuz sonuçlarla karşılaşma korkusu başka çalışmalarda da bahsediIen bir periyodik tarama engelidir (6). Geri kalanı da vakti olmadığı için yaptırmadığını belirtmiştir. PSM yaptırmama karşısındaki bu tutumlar, başka çalışmalarda da benzerdir (7). Çalışmamızda ortaya çıkan ve üzerinde durulması gereken durum, düzenli tetkik ve taramaların gereksiz bulunmasıdır. PSM ve taramaların vakit kaybına yol açtığı düşüncesi başka bir çalışmada da hastalar tarafından belirtilmiştir (8). Özellikle kanser taramaları ile ilgili olan bu tutumun hastaların sağlık algısı ile ilişkili olabilir (9). Halbuki bilindiği gibi kanser, erken tanı konulduğunda tedavisi mümkün olan fakat geç kalındığında mortal olabilen bir sağlık problemidir. Kanser taramalarının, tanı ve tedavideki gecikmeleri önlediği konusunda hastalara danışmanlık yapılmalıdır (10).

Çalışma sonuçlarında hastaların yaklaşık yarısının PSM hakkında eksik ya da hiç bilgisinin olmadığı görülmüştür $(10,11)$. PSM hakkındaki genel bilgi düzeyi çeşitli çalışmalarda değerlendirilmiş olup, ülkeden ülkeye ve çalışmanın yapıldığı topluma göre değişmektedir. Bu değişik bilgi düzeylerinin, çalışma yapılan bölgenin sosyoekonomik ve sosyokültürel düzeyine bağlı olduğu düşünülmektedir.

Tablo 4: Ailesinde kanser hastası olma durumunun bazı taramalarla ilişkisi

\begin{tabular}{|c|c|c|c|c|}
\hline & & \multicolumn{2}{|c|}{ Ailede kanser hastası } & \multirow[b]{2}{*}{$\mathbf{p}$} \\
\hline & & Evet & Hayır & \\
\hline \multirow[t]{2}{*}{ Daha önce GGK tahlili (50-70 yaş arası) } & Evet & 34 & 28 & 0,007 \\
\hline & Hayır & 39 & 76 & \\
\hline Toplam & & 73 & 104 & \\
\hline \multirow[t]{2}{*}{ Daha önce rahim ağzı kanseri için muayene (30-65 yaş arası kadınlar) } & Evet & 12 & 13 & 0,283 \\
\hline & Hayır & 78 & 133 & \\
\hline Toplam & & 90 & 146 & \\
\hline \multirow[t]{2}{*}{ Mamografi (40 yaş üstü kadınlar) } & Evet & 45 & 5 & $<0,001$ \\
\hline & Hayır & 5 & 75 & \\
\hline Toplam & & 73 & 104 & \\
\hline
\end{tabular}


Çalışma sonuçları, hastaların bazı sosyo-demografik özellik ve deneyimlerinin düzenli sağlık muayeneleri hakkındaki tutumları ile ilişkili olduğunu göstermektedir. Hastanın yaşı düzenli sağlık muayenelerini yaptırma durumunu etkileyen faktörlerin başında gelmektedir. Yine hastanın yaşı arttıkça bazı kanser taramalarını ve muayenelerini yaptırma durumunun arttığı görülmüştür. Hastanın yaşı arttıkça rahim ağzı kanseri ve meme muayenesi yaptırma durumu anlamlı olarak artmaktadır. Kanser gelişimi ve yaş arasındaki ilişkinin gösterilmiş olması bu eğilimi açıklayabilir. Nitekim pek çok çalışma yaşla birlikte kanser taramaları hakkında bilgi sahibi olma ve tarama yaptırma konusunda farklılık olduğunu söylemektedir $(12,13)$. Çalışmanın diğer bir sonucu, katılımcıların ailesinde kanser tanısı olan katıımcıların daha fazla tarama tetkiki yaptırmış olmasıdır. Bu durum doğal bir sonuçtur. Benzer şekilde diğer çalışmalarda da ailede kanser varlığı, hastaların kanser taraması yaptırması için önemli bir etki kaynağıdır $(14,15,16)$.

Meslek grubuna göre değerlendirildiğinde; çalışmadaki emekli olan bireylerin, hemen hemen yarısı olmak üzere diğer meslek gruplarına göre anlamlı olarak daha fazla PSM yaptırdığı tespit edilmiştir. Benzer şekilde emekli olan bireylerin daha fazla tarama tetkiki yaptırdığını söyleyen çalışmalar mevcuttur (17). Bu durum emekli insanların yaşının genellikle daha ileri olması ile açıklanabilir. Bir diğer sebep olarak ise emekli insanların kendi sağlıklarına daha fazla vakit ayırabiliyor olması şeklinde yorumlanabilir. Çalışmamızda evli olan katıımcıların daha fazla PSM yaptırdıkları tespit edilmiştir. Sağlık hizmetlerinden yararlanma oranları ve düzenli muayene alışkanlığı benzer şekilde evli olan insanlarda daha yüksek bildirilmektedir $(18,19)$.

Çalışma, birinci basamak kullanım alışkanlıklarına göre değerlendirildiğinde; katılımcıların büyük bir kısmı genel sağlık durumunu orta düzeyde olarak değerlendirmiştir. Çalışmaya katılan bireyler çoğunlukla aile hekimlerinden memnun olduğunu söyledi. Benzer şekilde Güven ve ark.nın yaptığı çalışmada da katıımcıların yarısından çoğunun aile hekimlerinden memnun olduğu görülmektedir (19). Birinci basamak ve koruyucu sağlık hizmetlerinin kullanımının artırımasının dolaylı olarak düzenli muayene ve tarama oranlarını artıracağını düşünmekteyiz.

Çalışma, sadece tek merkezde, kesitsel ve üçüncü basamak bir üniversite hastanesinde gerçekleştirildiği için sonuçları itibariyle genelleştirilemez. Ayrıca çalışma bir "anlık görüntü" araştırmasıydı ve katılımcıların kendi kendilerine bildirdiği bilgilerdi. Hastalar anketi cevaplarken acele etmiş, soruları tam okumamış ve çevresindeki insanlardan etkilenmiş olabilirler.

Çalışmamızda ortaya çıkan en önemli sonuç, katıımcıların büyük bir çoğunluğunun düzenli PSM ve tarama tetkiklerini yaptırmıyor olmasıdır. Tüm tavsiyeler yapıldıktan sonra PSM yaptırmak kişilerin onayına bırakılmaktadır. Eğer in- sanlarda periyodik muayene ve tarama tetkiklerinin gerekliliği konusunda bir farkındalık yoksa, koruyucu sağlık hizmetlerinde gelişen teknoloji ile birlikte pek çok imkân olmasına rağmen istenilen düzeyde koruyucu halk sağlığı geliştirilemez. Birinci basamak hekimlerinin bireyleri periyodik sağlık muayeneleri konusunda bilgilendirmesi gerekmektedir.

\section{Teşekkür}

Yok

Yazar Katkı Beyanı

Fikir: Zerrin Gamsızkan, Tasarım: Zerrin Gamsızkan, Abdulkadir Kaya, Veri toplama: Abdulkadir Kaya, Veri analizi: Abdulkadir Kaya, Literatür taraması: Zerrin Gamsızkan, Makale yazımı: Zerrin Gamsızkan, Abdulkadir Kaya.

\section{Çıkar Çatışması}

Çalışmamızda herhangi bir çıkar çatışması yoktur.

\section{Finansal Destek}

Bu çalışma için herhangi bir finansman kaynak kullanılmamıştır.

\section{Etik Kurul Onayı}

Çalışmamız için Düzce Üniversitesi Etik Kurulu onayı 15/03/2021 tarih ve 2021/73 numaralı karar ile alındı.

\section{Hakemlik Süreci}

Kör hakemlik sonrası yayınlanmaya uygun bulunmuş ve kabul edilmiştir.

\section{KAYNAKLAR}

1. Miyazaki K, Sato J, Mukohara K, Kitamura K, Saito S, Ban N. Attitudes of Japanese primary care physicians toward publicly endorsed periodic health examinations: A cross sectional survey. Asian Pac J Cancer Prev 2007; 8(2): 258-262.

2. Ersoy E, Saatçi E. Periyodik sağlık muayenelerine genel bakış Türk Aile Hek Derg 2017; 21 (2): 82-89.

3. Pashkov V, Noha P, Soloviov A. Screening and periodical medical examinations as important part of public health: Problem of the legal implementation. Wiad Lek 2018; 71(4): 893-896.

4. T.C. Sağlık Bakanlığı Türkiye Halk Sağlığı Kurumu. Periyodik sağlık muayeneleri ve tarama testleri 2015. http://www. thsk.gov.tr/dokumanlar/aile-hekimligi-egitim-gelistirme-dbdokumnalari.html adresinden 16.03.2021 tarihinde erişilmiştir.

5. Cherrington A, Corbie-Smith G, Pathman DE. Do adults who believe in periodic health examinations receive more clinical preventive services? Prev Med 2007;45(4):282-289.

6. Radi SM. Breast cancer awareness among Saudi females in Jeddah. Asian Pac J Cancer Prev 2013; 14(7): 4307-4312.

7. Malik IA, Gopalan S. Use of CAM results in delay in seeking medical advice for breast cancer. Eur J Epidemiol 2003; 18(8): 817-822. 
8. Al-Azri M, Al-Kindi J, Al-Harthi T, Al-Dahri M, Panchatcharam SM, Al-Maniri A. Awareness of Stomach and Colorectal Cancer Risk Factors, Symptoms and Time Taken to Seek Medical Help Among Public Attending Primary Care Setting in Muscat Governorate, Oman. J Cancer Educ 2019; 34(3): 423-434.

9. Şen SK, Öztürk YK. Sağlık Algısı ile Kanser Taraması Farkındalığı Arasındaki İlişki. Türk Aile Hek Derg 2020; 24 (4): 175-183.

10. Khan TM, Leong JP, Ming LC, Khan AH. Association of Knowledge and Cultural Perceptions of Malaysian Women with Delay in Diagnosis and Treatment of Breast Cancer: a Systematic Review. Asian Pac J Cancer Prev 2015; 16(13): 5349-5357.

11. Vuong QH. Survey data on Vietnamese propensity to attend periodic general health examinations. Sci Data 2017; 4:170142.

12. Bawazir A, Bashateh N, Jradi H, Breik AB. Breast Cancer Screening Awareness and Practices Among Women Attending Primary Health Care Centers in the Ghail Bawazir District of Yemen. Clin Breast Cancer 2019; 19(1): e20-e29.

13. Alshahrani M, Alhammam SYM, Al Munyif HAS, Alwadei AMA Alwadei AMA, Alzamanan SSM, Aljohani NSM. Knowledge, Attitudes, and Practices of Breast Cancer Screening Methods Among Female Patients in Primary Healthcare Centers in Najran, Saudi Arabia. J Cancer Educ 2019; 34(6): 1167-1172.
14. Uludağ G, Gamsızkan Z, Sungur MA. Kadınların Serviks Kanseri ve Taraması ile İlgili Sağlık İnançlarının değerlendirilmesi. Düzce Üniversitesi Sağlık Bilimleri Enstitüsü Dergisi 2020; 10(3): 357-362

15. Al-Azri M, Al-Rubaie K, Al-Ghafri S, Al-Hinai M, Murthi Panchatcharam S. Barriers and Attitudes toward Breast Cancer Screening among Omani Women. Asian Pac J Cancer Prev 2020; 21(5): 1339-1347.

16. Kwok C, Endrawes G, Lee CF. Cultural Beliefs and Attitudes About Breast Cancer and Screening Practices Among Arabic Women in Australia. Cancer Nurs. 2016; 39(5): 367-374.

17. Gan-Yadam A, Shinohara R, Sugisawa $Y$, Tanaka E, Watanabe T, Hirano M, Tomisaki E, Morita K, Onda Y, Tokutake K, Mochizuki Y, Matsumoto M, Sugita C, Anme T. Factors associated with health service utilization in Ulaanbaatar, Mongolia: a population-based survey. J Epidemiol 2013; 23(5): 320-328.

18. Girma F, Jira C, Girma B. Health services utilization and associated factors in jimma zone, South west ethiopia. Ethiop J Health Sci 2011; 21(Suppl 1): 85-94.W

19. Güven EA, Aycan S. Ankara'da Bir Üniversite Hastanesine Başvuranların Mevcut Aile Hekimliği Sistemi ve Sevk Uygulaması Hakkında Düşünceleri. ESTÜDAM Halk Sağlığı Dergisi 2018; 3(3): 25-36. 